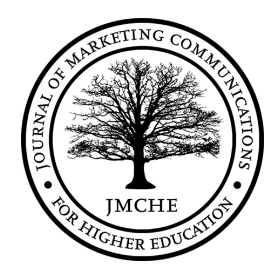

\title{
Referral Marketing in Online Higher Education: A Holistic Snapshot of Strategic Initiatives, Effectiveness and Opportunities in a leading International Organization
}

\author{
Elise Boros M.S. University of Roehampton London Online \& Angeliki Papasava Ph.D. \\ University of Roehampton London Online
}

\section{Introduction}

Contemporary marketing strategies in both retail and service sectors have developed vastly owing to cutting-edge technology, which has seen a boom in referral marketing (RM) practices and penetration of complex, interconnected social networks (Berman, 2016). At its ever-increasing pinnacle, social media technology and other technologies continue to advance ways in which marketers can reach and influence their audience (Alalwan et al., 2017); Clark et al., 2017; Orzan et al., 2016). Consequently, it is now more important than ever to have a consistent and innovative integrated marketing communication (IMC) strategy (Luxton et al., 2015; Vernuccio and Ceccotti, 2015). Rapidly advancing educational technology has given rise to the education technology (EdTech) industry and online higher education (OE), opening new channels for higher education providers to reach their audience. Allied to that, the compound annual growth rate in the next 10 years for the global e-learning market has been projected at $7.2 \%$, nearing a staggering $\$ 325$ billion (NGNW, 2017). In 2016, a survey showed that $88 \%$ of corporate recruiters were seeking to hire recent MBA graduates (GMAC, 2016). The aim of this study was to critically analyse the effectiveness of the referral marketing strategy through the multifocal lens of the enrolment team and current students, its challenges and opportunities, within the framework of OE. The researchers believe the benefit of achieving this outcome will be the resultant impact on marketing success and profitability.

\section{Problem Statement: Understanding Referral Marketing in Higher Education Online} So noticeable is the scarcity of research into the topic of modern-day RM, particularly in the OE or higher education industry that one must draw on the findings from other industries. The seemingly abstract concept of consumer brand engagement (CBE) has previously proved to be an elusive metric for marketing professionals to gauge. Nonetheless, there is a consensus on the interplay between CBE and corporate success which indeed extends to RM. Factors linked with increasing engagement include behaviours such as word-of-mouth (WOM) and electronic WOM (EWOM) generation. These are of particular interest to RM specialists. Social media channels such as Facebook, Twitter, and Linkedin are now fully integrated to support targeted marketing campaigns, making EWOM more abundant and trackable than ever. In light of this global trend, many OE institutes are utilising these channels to drive lower-cost student recruitment. Consumer relationship management (CRM) took root in the 1990s and was a critical step in building a loyal consumer base. Yet as technology has advanced to tender more robust and sophisticated CRM systems, the extension into an RM strategy focuses on retention and maximisation of loyal consumers, particularly in the OE sector. Online marketing, online reviews, blogs, and social media have led to a gradual paradigm shift in student recruitment. In other industries such as banking and retail, RM has become a lucrative and extensively implemented strategy and the researchers

(C) 2020 Elise Boros M.S., Angeliki Papasava Ph.D.

This open access article is licensed under a Creative Commons Attribution-NonCommercial license. DOI: JMCHE/v1i301 


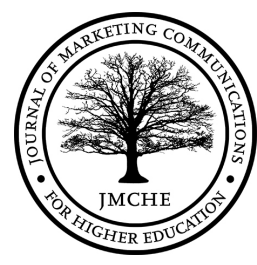

believe it has not yet reached its potential in OE. OE is a service that requires students to continue studying and interacting with the institution for extended periods of time. In this sense, coupled with high student fees, $\mathrm{OE}$ can be regarded as a high involvement purchase. When considering WOM and EWOM generation, incentivisation is an effective tool (Ryu and Feick, 2007; Mengze and Wojnicki, 2014). This principle forms the basis of an incentivised RM strategy, yet 'referral marketing' is distinguished by targeting existing clients to refer new consumers that have a 'high lifetime value' (Berman, 2016).

\section{Statement of Purpose}

Through the assessment of experienced practitioners' feedback of a leading OE institution, the researchers' aim is to display a holistic snapshot of the current RM strategy, steering away from assessing the traditional dyadic consumer-brand relationship focussed on by extant RM literature (Chan et al., 2014; Lee and Anantharaman, 2015; Garnefeld, et al., 2013; Shi and Wojnicki, 2014; Hennig-Thurau et al., 2001). A case study of this magnitude allows the researchers to deduce and propose a conceptual model for an effective RM strategy for the OE sector. The adoption of a two-part, mixed-methods analysis followed a constructivist approach, involving both qualitative and quantitative research methods and data analysis, and sought to gain insight into expert opinion on RM definition, key RM dimensions in an effective RM strategy, related contemporary issues, and recognition of emerging opportunities to adapt the current strategy in this unique industry. A quantitative survey enquiring into students' logic for referring was also conducted and compared/contrasted with the experts' feedback. The present study endeavoured to pioneer $\mathrm{RM}$ research in $\mathrm{OE}$ whilst developing on key extant literature to further understand how to implement a successful RM strategy in OE at all marketing levels of an organisation.

As opposed to simply investigating trends and behaviours of consumers on which much of the research in the field is focussed, this research aimed to mainly embrace a focus to the executive's approach, complemented by student feedback. On this premise, a case study was built to show a snapshot of the current referral strategy in an international OE company. Research questions were carefully chosen to identify constructs and conceptual elements, both internal and external, which were perceived to influence the efficacy of the existing RM strategy whilst illustrating a holistic snapshot, whence actionable managerial insights can be derived. Internal and external factors refer to influential elements occurring inside and outside the organisation respectively.

\section{Research Questions and Objectives}

The current study explored defining features of an RM strategy in a multinational OE organisation. After consideration of the current environment and identified gaps in extant literature, the following broader research questions were proposed, specific to the OE sector:

1. How do elements of organisational commitment lead to a successful RM strategy?

2. What are the influential dimensions of RM in OE?

3. What are the key trends in RM in the OE sector (related to influential dimensions)?

(C) 2020 Elise Boros M.S., Angeliki Papasava Ph.D.

This open access article is licensed under a Creative Commons Attribution-NonCommercial license.

DOI: JMCHE/v1i301 


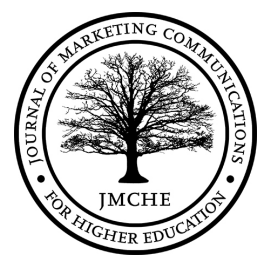

Given the constructivist nature of the research in seeking to empirically and inductively conceptualise successful RM strategy in OE, the research aims to explore employees' subjective involvement, knowledge and opinions in regard to RM strategies. To delineate the aims of the study more specifically, the research objectives are introduced below:

- Discover how employee engagement influences the current RM strategy

- Establish the influential dimensions of RM in the OE sector

- Determine the perceived impact of IMC on the success of the RM strategy

- Identify key trends, challenges and opportunities in RM in an OE setting

\section{Rationale and Significance}

Since much of related research falls outside of OE, the current study links extant RM literature from other industries with the international OE sector. On the foundation that the higher education sector, and more specifically the OE sector, is unique and relatively new, the researchers believe that findings from other contexts are not directly comparable. Therefore, this research into the higher online education sector is warranted.

RM has the growth potential to form a significantly dominant strategy, particularly due to its advantages of reduced cost per lead, increased consumer loyalty, increased consumer satisfaction, increased consumer engagement, increased retention and increased student success (Berman, 2016; Schmitt et al, 2011; Shi and Wojnicki, 2014).

Referrals are typically more valued consumers, with increased loyalty and better retention rates (Schmitt et al, 2011). Therefore, in terms of profitability and reputation, it is believed that universities and higher education institutes can benefit from the findings of such research.

The current case study aimed to delineate presently implemented RM practices in the organisation of interest whilst illustrating impacts of interdepartmental efforts, effectiveness, opportunities and challenges. By gaining a deeper understanding of the mechanisms behind $\mathrm{RM}$, marketers and OE specialists can streamline RM strategies to increase return on investment, student retention, and the overall student experience.

The originality and value of this study are threefold, as it contributes to the body of knowledge concerning strategic RM, specifically in higher education online where research is lacking. Secondly, it complements existing literature on this unique marketing concept in terms of contemporary and practical managerial insights, whilst providing a framework that can potentially contribute to future marketing and/or behavioural theory.

\section{Generalisation of Results}

Genaralisation as a research practice is a logical way of argumentation in order to extend the researcher's claims beyond the data and creating a connection between the studied events with the ones that were not studied. There is no methodology that is exempted from the need to demonstrate a compelling argument and logic of generalisation (Steinberg, 2015).

(C) 2020 Elise Boros M.S., Angeliki Papasava Ph.D.

This open access article is licensed under a Creative Commons Attribution-NonCommercial license. DOI: JMCHE/vli301 


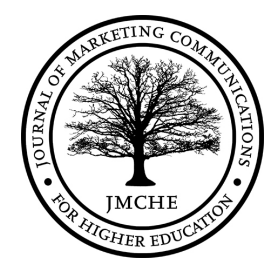

However, the most criticised element of case studies is generalisability (Woodside, 2010). Also, case studies receive criticism about their external validity (Byrne \& Ragin, 2009). Taking into account this criticism, the researchers decided to use triangulation in order to ensure the validity of the followed methodology.

Case study research has the potential to deal with various situations, ranging from simple to complex. Using case studies, researchers can answer "how" and "why" type questions, while taking into consideration how a phenomenon is influenced by the context within which it is situated. (Baxter \& Jack, 2008). Case study generalisations can be viewed as an effort to generalise from a small number to a larger population of cases in order to learn from one case and to understand many (Yin, 2013; Campbell, 2003). Without generalisation our interaction with our world could not be coherent as generalisation is a part of our cognitive capabilities (Ruddin, 2006; Robinson \& Norris, 2001).

Even so, the generalisation of case results is rather difficult, especially to other contexts than the one studied (Firestone, 1993). There are researchers who would not draw conclusions from case studies, especially from single cases due to this. The authors of this paper decided to take the risk as the chosen organisation is one of the largest representing online higher education and has many universities around the world as its customers. Even though the data came from a single organisation, they are not bound to a single university.

The researchers have also considered the term 'naturalistic generalization' or 'transferability' for this case study (Sheldon, Lincoln \& Guba, 1986). The implication of these ideas is that case study readers should determine themselves if the findings are applicable to cases other than the ones that the researchers studied. The authors of this paper agree with this and believe that it is applicable to their case study. Viewed this way, the burden of proof could be on the reader instead of the researcher, although it is the researcher's responsibility to provide the reader with a sufficient description of the case study. This way, the researcher allows readers to assess the degree of similarity between the investigated case study and the cases to which the findings can be applied (Lincoln \& Guba, 1989).

Although the literature is discrepant, it is mostly suggested that case studies may be generalised in the same way that statistical studies are, provided that the generalisation is done correctly (Wikfeldt, 2019). Taking this into consideration, the researchers did their best, considering the circumstances, to perform a case study that is valid and reliable and also discussed the drawbacks, research limitations and recommendations for future research in this paper.

\section{Materials and Methods}

\section{Overview}

The critical literature review presents and contrasts relevant literature whilst comparing theoretical perspectives related to RM, organisational commitment, $\mathrm{CBE}$ and IMC. The researchers continue to discuss these topics in more detail and firstly focus on organisational commitment as a mediating construct to introduce its potential impact on RM strategy

(C) 2020 Elise Boros M.S., Angeliki Papasava Ph.D.

This open access article is licensed under a Creative Commons Attribution-NonCommercial license.

DOI: JMCHE/v1i301 


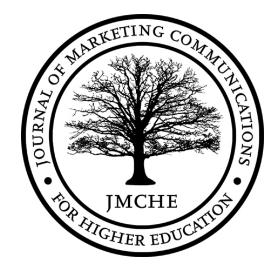

success. Secondly, the larger part of the study focuses on critically analysing theory and research related to antecedents of referral behaviour. This process forms a diagnostic foundation upon which the researchers' findings can be built.

\section{Examination and Critical Review of Theoretical Perspectives and Paradigms}

The researchers have chosen to critically evaluate the literature in relation to the research questions by organising them into two parts. These will relate to research question one, then research questions two and three respectively. Research questions two and three have been grouped together since the researchers seek trends that are linked with referral dimensions.

\section{Critical Analysis of Organisational Commitment and Employee Engagement}

Organisational commitment has been defined as being impacted by, and made up of, several different constructs by different researchers (De Nobile, 2017; Nketia, 2016; Tan and Lau, 2012), yet others also refer to organisational commitment as overlapping with organisational culture (Khouly and Fadl, 2016), both of which have been found to impact on organisational performance and success of strategic initiatives (Hanaysha, 2016; Khouly and Fadl, 2016; Tan and Lau, 2012). Hanaysha's (2016) conceptual framework classifies factors which shape organisational commitment in a case study on a university. Hanaysha (2016) only investigated three variables on organisational commitment in university staff, which is not related to engagement or strategy nor is comprehensive enough. The researchers seek to understand what other variables exist in commitment to RM strategy so that OE senior leadership can make more informed strategic decisions. In contrast, De Nobile (2017) finds that elements of communication more directly impact on commitment and engagement.

The researchers are most interested in employee engagement (EE) in terms of commitment to strategy, and they recognise a gap here. Given the lack of clarity and understanding, this study sought to understand how elements of organisational commitment were impacting the success of the RM strategy in OE. A positive effect on organisational commitment has been documented when taking an Open Strategy (OS) approach (Nketia, 2016) including an increase in the quality of strategic initiatives (Gast and Zanini, 2012). An OS approach can be defined as promising 'increased transparency and inclusion regarding strategic issues, involving both internal and external stakeholders,' (Hautz et al., 2017). This approach is particularly relevant when attempting to optimise the current RM strategy for this case study. However, there are disadvantages, including dilemmas of process, commitment, disclosure, empowerment and escalation.

\section{Consumer Brand Engagement}

Understanding conceptual elements of CBE is a relatively recent endeavour that is not yet fully understood (Dwivedi, 2015; Hollebeek, 2011), thus exposing a gap in the literature. Deemed as an extension of relationship marketing, CBE has been defined as:

The intensity of an individual's participation in and connection with an organization's offerings and/or organizational activities, which either the customer or the organization initiate. (Vivek et al., 2012)

(C) 2020 Elise Boros M.S., Angeliki Papasava Ph.D.

This open access article is licensed under a Creative Commons Attribution-NonCommercial license. DOI: JMCHE/vli301 


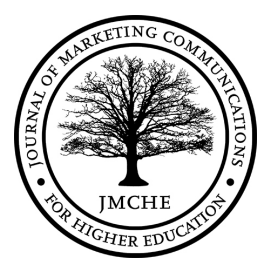

In a wider scope, elements such as trust, loyalty, WOM, value and affective commitment appear in the theoretical model by Vivek et al (2012). Such elements are common ground in referral behaviour research and relationship marketing (Cetinā et al., 2014; Shi and Wojnicki, 2014; Sarathy and Patro, 2013; Shao et al., 2014; Schumann et al., 2010; Vivek et al., 2012; Yoo et al., 2015) thus the researchers expect these will play a role in educational RM also.

\section{Cognition to Action Loyalty Framework and IMC}

An alternative approach to demonstrating CBE, Oliver's (2014) cognition-to-action loyalty framework appears as more streamlined compared to that of Vivek et al (2012). Where Oliver (2014) finds a positive impact of cognitive loyalty on action loyalty, further research into cognitive processing by Leckie et al. (2016) finds a negative correlation with brand loyalty. Due to this discrepancy, the researchers aimed to distinguish what type of relationship, if any, there was between the constructs of Cognitive, Affective and Conative Loyalty on Action Loyalty, with the aim to build on the theoretical conceptual framework in an OE context.

Oliver (2014) delineates each phase as emotional brand preference (Cognitive), attitudinal (Affective) and behavioural intention (Conative). Action Loyalty is the by-product, and in this case, is considered as the referral behaviour itself. A similar model by Graffigna and Gambetti (2015) replaces these stages with 'friendship', 'intimacy', and 'symbiosis', however, is less of a linear model and more abstract to apply in a managerial context. The conceptual IMC model by Batra, R. and Keller, K. (2016) matches the stages set out by Oliver's (2014) cognitive, affective and conative stages, but in a more continuous fashion. It aims to fully demonstrate how a comprehensive IMC strategy can reflect a scope of stages from the cognitive through to the affective stages of loyalty and CBE.

\section{Loyalty and Trust in Referability}

Referral Marketing has many constructs in common with relationship marketing including satisfaction, trust, loyalty and perceived quality and commitment (Berman, 2016; HennigThurau et al., 2001; Perin et al., 2012). On this premise, fundamentals of preserving student loyalty should be upheld in a successful RM strategy. Brand loyalty is often deemed as a competitive advantage, synonymous with greater consumer equity (Hennig-Thurau et al., 2001; Lee and Anantharaman, 2015). Antecedents of student loyalty are primarily perceived quality and trust (Perin et al., 2012).

Berman's (2016) research explores referability with stark references to consumer lifetime value (CLV), an essential yet elusive metric. Berman (2016) considers RM as separating out satisfied consumers from which to generate referred business with higher conversion. Although the current study does not seek to understand this metric, it is an important concept and driver for a better understanding of RM research.

\section{Co-creation}

The concept of co-creation has also become influential in the topic of RM. The generation of EWOM has ballooned drastically with increasing social media channels which thrive on EWOM and act as platforms for co-creation. A vague definition of co-creation is the 'value'

(C) 2020 Elise Boros M.S., Angeliki Papasava Ph.D.

This open access article is licensed under a Creative Commons Attribution-NonCommercial license. DOI: JMCHE/vli301 


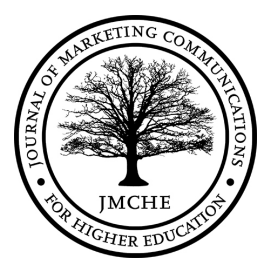

that clients themselves construct (Zwass, 2010). The two concepts of social media and cocreation are so closely intertwined that social media has been defined as:

One media type with one differentiating characteristic: They blend technology and social interactions for the co-creation of content and value. That is, people use them for social interactions and conversations.(Strauss and Frost 2013)

With the recognised importance of co-created content on consumer purchase behavior in university choice (Yang and Mutum, 2015), marketers can appreciate the value of co-creation as part of a successful RM strategy. This is linked with a comprehensive IMC strategy and branches into the social media domain, and could potentially increase loyalty as it has done in other industries (Cossío-Silva et al., 2016).

\section{Customer Lifetime Value and Relationship Marketing}

$\mathrm{RM}$ is an antecedent of referral behaviour and is a critical element of customer-lifetime value, with much marketing strategy now focusing on increasing CLV (Haenlein and Libai, 2017; Vivek et al., 2012). The researchers believe RM provides an excellent opportunity to do so. Recently published research found that soliciting consumer feedback using positive openended questions leads to a higher CLV (Bone et al., 2017). CLV is also positively linked with attitudinal loyalty (Reichheld, 1993), which is in turn linked with value creation (Hsieh and Chang, 2016). However, concernedly none of these mention RM. CLV as a construct is particularly of interest to marketers in OE because a student's status evolves from a prospective student to a student, where retention is key. The final phase is as an alumnus, which is a unique consumer state given that most alumni are often no longer paying customers. In order to increase CLV, the researchers argue RM marketing is a possible solution.

\section{Summary and Definition of Research gaps}

The researchers found a lack of peer-reviewed literature in this newly burgeoning area of RM in OE. Embarking on university study is a high-involvement purchase (Mazzarol and Soutar, 2002), however, most related studies revolve around understanding and harnessing consumer motivations towards referral generation in low involvement purchases (Chan et al., 2014; Mengze and Wojnicki, 2014; Verlegh et al., 2013).

Most research focuses outside the education industry, but as OE is growing and EdTech is becoming increasingly mainstream, the researchers recognise a need to define RM in this unique industry. Studies by Chan et al. (2014) suggest further research is needed into referral programmes of varying sectors, given the unique RM dimensions and consumer behaviours. Hanaysha (2016) only investigated three variables on organisational commitment in university staff, however, the researchers seek to understand what other variables exist in commitment to RM strategy so that OE senior leadership can make more informed strategic decisions. Keeping in mind the multifaceted nature of organisational commitment, being impacted by OS, the researchers intended to uncover new insights into how this may affect the success of the current organisation's RM strategy. Related to existent CBE theory, the

(C) 2020 Elise Boros M.S., Angeliki Papasava Ph.D.

This open access article is licensed under a Creative Commons Attribution-NonCommercial license. DOI: JMCHE/v1i301 


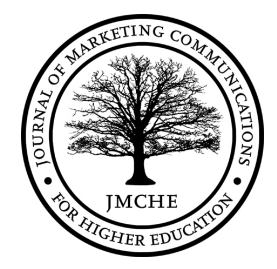

current study aimed at understanding the relationship of perceived CBE with RM strategy and referral behaviour in online education. Social cognitive theory (SCT) will also be explored to see if and how it relates to RM strategy in OE.

Lastly, Berman (2016) offers a seemingly comprehensive review of RM, however, the industries compared do not include education or high involvement purchases. From a critical perspective, the researchers cannot extrapolate such theory if the uniqueness of $\mathrm{OE}$ is not enveloped in the theoretical design. Thus, the researchers deem it necessary to extend RM knowledge to the OE sector.

\section{Methodological Approach}

The researchers were drawn to mixed methodology, as it is linked with increased generalisability, reliability and validity of conclusions and thus favoured for this case study. Mixed-methods research has been described as 'expansive', 'pluralistic', and 'complementary' (Johnson and Onwuegbuzie, 2004). Quantitative research was considered due to its strength in identifying causal relationships (Easterby-Smith, 2012; Hanaysha,2016). The current research aims not only to expose causal relationships but also to explore unique and complex dimensions of RM in OE with the aim of contributing to theory. Given the scope and professional nature of the study, in-depth interviews were selected to explore experts' feedback and input on RM strategy as they provide a greater level of detail than online surveys, which is valuable for professional applications (Hinge, 2014). Conversely, online surveys were considered for capturing insights from students as they have a wide reach and are time efficient for the level of information sought from students to complement the qualitative data (Easterby-Smith et al., 2012; Hinge, 2014). Holistic research on the topic has relied on secondary data, (Berman, 2016; Daj and Chirca, 2009; Fong, 2013). Their contributions to RM marketing research and their varied approaches provided a comprehensive view of the current understanding of the topic, but the researchers argue this is not enough.

\section{Qualitative Research Design and Instrument}

Template analysis is a comparatively novel approach to understanding qualitative data (Waring and Wainwright, 2008). The researchers used thematic analysis which firstly involved open coding, followed by axial coding and finally selective coding to categorise leading themes (Hardy and Bryman, 2009; Johnson, 2015b). By conducting semi-structured interviews with participants, the researchers aimed to incorporate opinions, which to some degree included elements of narrative methods. Narrative methods form another group of constructionist research designs that have been used particularly in marketing and strategy research, due to their ability to draw emotional insight and consumer beliefs (Haase et al., 2013; Johnstone et al., 2013; Lobstein et al., 2017; Melewar et al., 2014).

\section{Qualitative Population Sample and Organisational Profile}

The unnamed multinational organisation chosen for the study offers higher education programmes online to students based domestically and internationally. The programmes offered are UK-based, fully accredited post-graduate programmes with international

(C) 2020 Elise Boros M.S., Angeliki Papasava Ph.D.

This open access article is licensed under a Creative Commons Attribution-NonCommercial license. DOI: JMCHE/vli301 


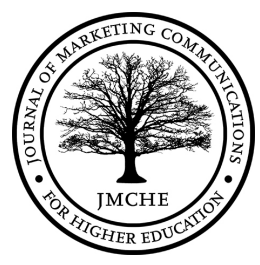

recognition. The referral strategy in place is incentivised, where students who refer new students are rewarded with financial credit towards their studies. The population of interest was staff of the organisation that execute a marketing and sales role related to the referral strategy. The entire team of 24 executives was invited, and 22 agreed to an interview $(92 \%$ response rate). Saturation was reached after 15-18 interviews as all overarching codes appeared, however, the researchers continued to interview the few remaining to ensure complete saturation. As participants were selected from the population of interest, it was assumed that their viewpoints were highly likely to mimic others' in the sample population (McQuarrie and McIntyre, 2014).

\section{Qualitative Data collection and analysis}

If not carefully guided, qualitative interviews can result in data that does not specifically answer the research questions (Easterby-Smith et al., 2012), yet questions should incite a personal response that is not too restricted (Johnson, 2015a). As a result, 8 open-ended questions, that had been adapted from the literature (Cetinā et al., 2014; Ilgaz and Gülbahar, 2015), were targeted towards the research aims. They followed a partially structured Skype interview approach with interviews recorded, then later played back to transcribe. These questions allowed for open answers to explore employees' unique perceptions, opinions and feelings towards the various elements of the organisation's RM strategy. Semi-structured interviews lasting approximately 18 minutes each on average were conducted and audio recorded using Skype from 20/06/2017 to 23/06/2017. Table 1 lists the profiles of the 22 participants.

\begin{tabular}{|c|c|c|c|c|c|c|c|c|c|c|c|}
\hline Measure & Item & $\mathrm{N}$ & $\begin{array}{l}\text { Pct } \\
(\%)\end{array}$ & Measure & Item & $\mathrm{N}$ & $\begin{array}{l}\text { Pct } \\
(\%)\end{array}$ & Measure & Item & $\mathrm{N}$ & $\begin{array}{l}\text { Pct } \\
(\%)\end{array}$ \\
\hline \multirow[t]{3}{*}{ Gender } & Female & 10 & $45 \%$ & \multirow[t]{3}{*}{ Position } & Manager & 2 & $9 \%$ & $\begin{array}{l}\text { Age } \\
\text { Bracket }\end{array}$ & $25-35$ & 15 & $68 \%$ \\
\hline & \multirow[t]{2}{*}{ Male } & 12 & $55 \%$ & & Consultant & 5 & $23 \%$ & & $36-45$ & 5 & $23 \%$ \\
\hline & & & & & Consultant & 15 & $68 \%$ & & $46-55$ & 2 & $9 \%$ \\
\hline \multirow[t]{5}{*}{ Tenure } & $\begin{array}{l}<1 \mathrm{yr} \\
1 \mathrm{yr}-3\end{array}$ & 1 & $5 \%$ & \multirow{5}{*}{ Education } & & & & \multirow{5}{*}{ Location } & $56-65$ & & \\
\hline & $\begin{array}{l}\text { yrs } \\
\text { 3yrs- }\end{array}$ & 11 & $50 \%$ & & & & & & & & \\
\hline & $\begin{array}{l}5 \mathrm{yrs} \\
5 \mathrm{yrs}-\end{array}$ & 7 & $32 \%$ & & No degree & 3 & $14 \%$ & & Netherlands & 16 & $73 \%$ \\
\hline & $10 \mathrm{yrs}$ & 2 & $9 \%$ & & Undergraduate & 11 & $50 \%$ & & Poland & 4 & $18 \%$ \\
\hline & $>10 \mathrm{yrs}$ & 1 & $5 \%$ & & Post Graduate & 8 & $36 \%$ & & United States & 2 & $9 \%$ \\
\hline
\end{tabular}

Table 1: Profile of Respondents: Qualitative Interviews $(\mathrm{N}=22)$

During this stage of data conceptualisation, primary themes and codes were established. Therefore, an iterative process took place where finally similar themes were merged to form higher constructs to draw concise and relevant conclusions (Easterby-Smith et al., 2012). Prescriptive themes of Engagement, Influential Factors and Trends were applied initially and then adapted to the data. Data were coded according to emergent themes, then categorised into nodes. A mind map of themes was constructed using NVIVO 10 and hierarchical charts displayed the relationships between clusters to identify prominent themes.

(C) 2020 Elise Boros M.S., Angeliki Papasava Ph.D.

This open access article is licensed under a Creative Commons Attribution-NonCommercial license. DOI: JMCHE/vli301 


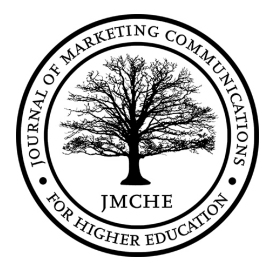

\section{Quantitative Research Design and Instrument}

The data collection instrument used was a free online survey provided by Survey Monkey. It allowed for a maximum of 10 questions to be asked, and a maximum of 100 respondents. It allowed for anonymity and had a setting to prevent multiple responses.

\section{Quantitative Population and Sampling}

The population of interest was active students studying a variety of online programmes at the unnamed online UK institute. At the time, there were approximately 4000 active students (Table 2).

\begin{tabular}{|c|c|c|c|c|c|c|c|c|c|c|c|}
\hline Measure & Item & $\mathrm{N}$ & $\begin{array}{l}\text { Pct } \\
(\%)\end{array}$ & Measure & Item & $\mathrm{N}$ & $\begin{array}{l}\text { Pct } \\
(\%)\end{array}$ & Measure & Item & $\mathrm{N}$ & Pct (\%) \\
\hline \multirow[t]{2}{*}{ Gender } & $\begin{array}{l}\text { Female } \\
\text { Male }\end{array}$ & 36 & $\begin{array}{l}36 \% \\
62 \%\end{array}$ & Source & $\begin{array}{l}\text { Referred } \\
\text { Non Referred }\end{array}$ & 32 & $\begin{array}{l}32 \% \\
68 \%\end{array}$ & Behaviour & $\begin{array}{l}\text { Referred } \\
\text { others } \\
\text { Not referred } \\
\text { others }\end{array}$ & 58 & $42 \%$ \\
\hline & Undisclosed & 2 & $2 \%$ & & & & & & & & \\
\hline \multirow{6}{*}{$\begin{array}{l}\text { Age } \\
\text { Bracket }\end{array}$} & & & & Education & No degree & 11 & $11 \%$ & Engagement & Highly & 63 & $63 \%$ \\
\hline & $25-35$ & 43 & $43 \%$ & & Undergraduate & 58 & $58 \%$ & \multirow{5}{*}{ Satisfaction } & $\begin{array}{l}\text { Somewhat } \\
\text { Not }\end{array}$ & 30 & $30 \%$ \\
\hline & $\begin{array}{l}36-45 \\
46-55\end{array}$ & $\begin{array}{l}39 \\
13\end{array}$ & $\begin{array}{l}39 \% \\
13 \%\end{array}$ & & $\begin{array}{l}\text { Post Graduate } \\
\text { Doctoral }\end{array}$ & $\begin{array}{r}30 \\
1\end{array}$ & $\begin{array}{r}30 \% \\
1 \%\end{array}$ & & engaged & 7 & $7 \%$ \\
\hline & $56-65$ & 4 & $4 \%$ & & & & & & Encouraged & 66 & $66 \%$ \\
\hline & $66-75$ & 1 & $1 \%$ & & & & & & Neutral & 17 & $17 \%$ \\
\hline & & & & & & & & & Discouraged & 16 & $16 \%$ \\
\hline
\end{tabular}

Table 2: Profile of Respondents: Quantitative Survey $(\mathrm{N}=100)$

\section{Quantitative Data collection and Analysis}

Students of the unnamed university were invited to participate by posting a series of three invitations (one initial, and two reminders) in the student social network. In the invitation post, a link to the online survey was shared. Because a plea for help was the only soliciting variable successful in increasing online survey participation in a previous study (Petrovčič et al., 2016), the invitation was positioned as a plea for students to help to contribute towards the current research. The research design comprised two pages with 10 questions in total - the maximum number of questions allowed in the trial version. The maximum number of 100 participants was reached.

\section{Results}

\section{Overview}

In this part, the analysis and findings of both qualitative and quantitative data are discussed in relation to the objectives of the study set out in the Introduction. The mixed methodology provided insightful data and gave methodological validity (triangulation) which has been also successful in previous studies (Drouin et al., 2015; Ilgaz and Gülbahar, 2015; Schaap et al., 2011). The researchers set out to discover RM dimensions in an OE setting, as well as the 


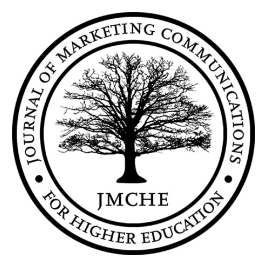

role of EE on its success. According to OE executives, student experience, satisfaction and culture were the top three influential factors contributing to the success of RM strategy in this case study. Findings echoed theory posited by Hennig-Thurau et al (2001) in the relationship quality-based student loyalty (RQSL) model. Indeed, also the level of student engagement was found to impact positively on referral behaviour, however, there was no discovered relationship between student satisfaction and referral behaviour. Interestingly, flexibility and professional applicability, and support related themes were the self-rated major drivers of students' referral intentions.

Secondly, EE was found to impact the success of RM primarily through organizational incentivisation, teamwork and training. Findings were in line with theory posited by Hanaysha (2016), Kaur (2017) and Gupta (2015), however, a new theme of 'belief' in the strategy was the most commonly voiced theme under the Engagement construct. Lastly, the researchers aimed to identify trends, and, apart from incentivisation, the main trends were found to be social media, geotargeting and outreach at key touchpoints which also echoed recent literature (Wind and Hays, 2016; Wright, 2014). Findings are discussed further below in relation to each of the research questions. To maintain anonymity of participants, gender appropriate pseudonyms have been employed with accurate demographic data.

\section{Data Analysis}

The researchers conducted a series of Pearson chi-squared tests using $0.05 p$ value as the level of statistical significance as deemed appropriate by Chu (1999). For chi-squared tests with greater than $20 \%$ cells with an expected count less than 5 , the likelihood ratio (LR) was considered as the measure of significance. Where data did not meet the assumptions of the Pearson Chi-Squared test, a Mann-Whitney Test was implemented. Degrees of freedom appear in parentheses and findings are presented and discussed in more detail below. Qualitative analysis was conducted through NVIVO (2017a), qualitative research software, with further discussion below.

\section{Factors influencing EE with the current RM strategy}

NVIVO calculates the cluster analysis by employing 'an iterative multidimensional scaling algorithm' (NVIVO, 2017b). Jaccard's index was used in all cluster analyses and is calculated through the following algorithm:

$$
J(A, B)=\frac{|A \cap B|}{|A \cup B|}=\frac{|A \cap B|}{|A|+|B|-|A \cap B|}
$$

A cluster analysis chart was created by word similarity for EE. Jaccard's index facilitates the understanding of the similarity between key factors, where nodes with similar coding are grouped together at an earlier stage than those that are less alike (NVIVO, 2017b).

IMC and interdepartmental communication were found to severely impact $\mathrm{EE}$ and is

(C) 2020 Elise Boros M.S., Angeliki Papasava Ph.D.

This open access article is licensed under a Creative Commons Attribution-NonCommercial license.

DOI: JMCHE/v1i301 


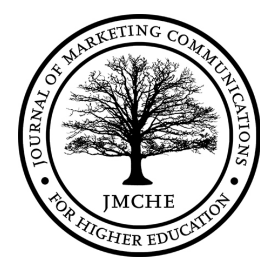

discussed in more detail later in the chapter. This is consistent with a comprehensive literature review of 65 empirical articles by Kaur (2017), however in the list of antecedents below deemed specific to the Education industry, 'Belief in Strategy' or a similar concept is not listed.

'Belief in Strategy' was mentioned by $100 \%$ of participants interviewed, with 41 references. This most closely correlates with Hanaysha's (2016) construct of Empowerment, however, 'empowerment' is defined as 'a motivational practice that aims to increase the performance by increasing the opportunities of participation and involvement in decision making'. Therefore, the researchers propose that employee 'Belief in Strategy' should be considered as a new construct.

\section{Overall Influential dimensions}

Once interviews were transcribed, data was entered into the software package NVIVO for coding and analysis. In NVIVO, codes are referred to as 'nodes'. Quantitative statistics from the surveys were coded and entered into SPSS for analysis. Both packages allow for hierarchical cluster analysis for group identification (identifying emerging themes) and multivariate analysis.

Emerging themes were entered into a mind map (Figure 1) to enable the researchers to determine interactions between various factors and resultant referral behaviour. 


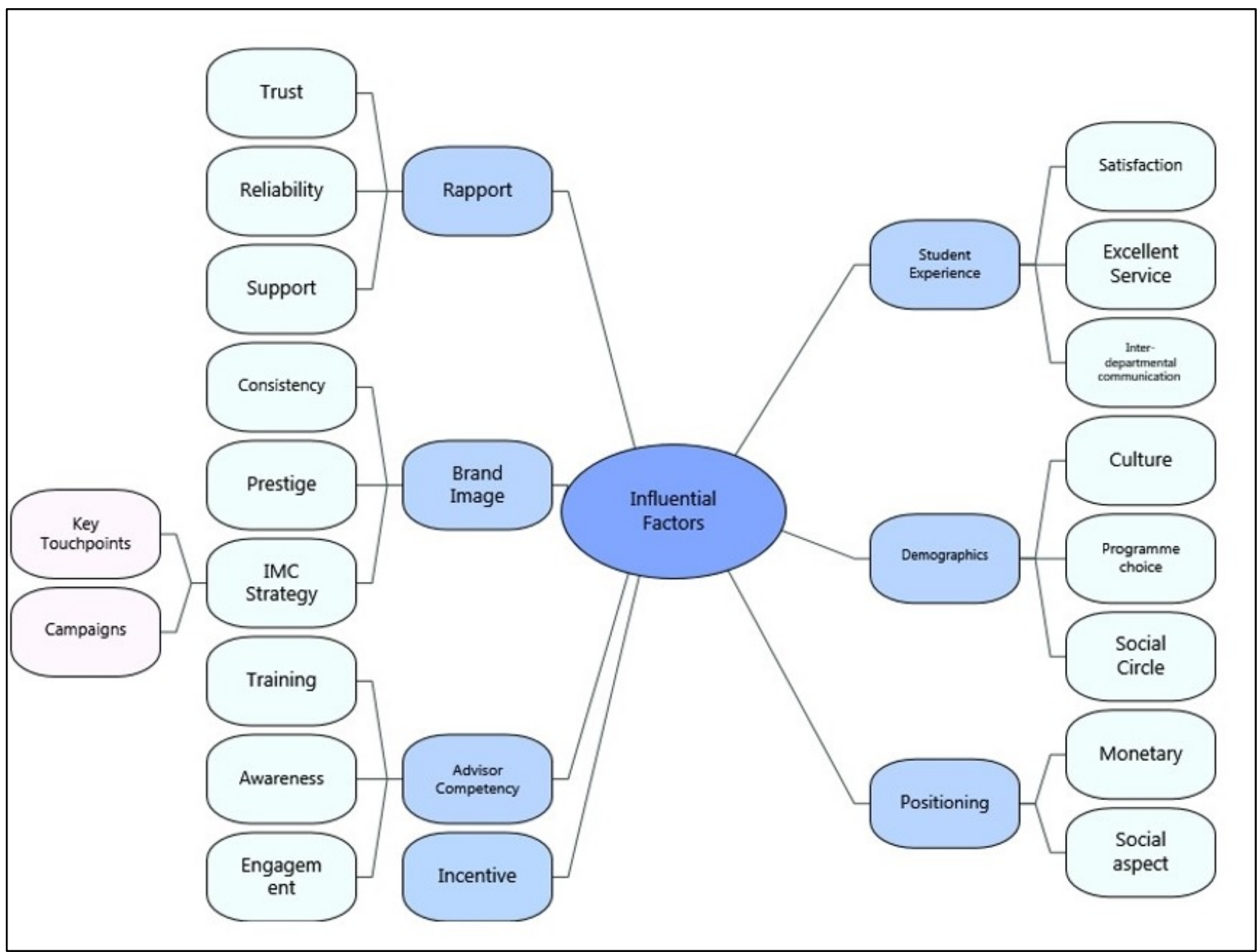

Figure 1. Mind Map of RM Dimensions from an Executive's Perspective (source: the authors)

A cluster analysis was also created by word similarity for referral dimensions. The data reveal the complex nature of RM in this sector, and those which stood out were Student Experience (12 sources, 33 references), Interdepartmental Communication (14 sources, 30 references) and Rapport (12 sources, 23 references). The dimensions of student experience (22 aggregated sources, 124 aggregated references) and challenges (22 aggregated sources, 116 aggregated references) both have the most influence on referral behaviour compared with Demographics, Advisor Competency, Incentive, Opportunities, Rapport, Brand Image and Positioning. These findings were softly echoed by data from students, which pointed to the strongest influential dimensions related to student experience (Figure 2 student data on dimensions) and referral behaviour increasing with levels of satisfaction (Figure 3 student data below). However, multivariate analysis in SPSS found there was no statistically significant association between Satisfaction vs. referral behaviour in the sample, $\chi^{2}(2)=$ $0.97, p=0.953$. 


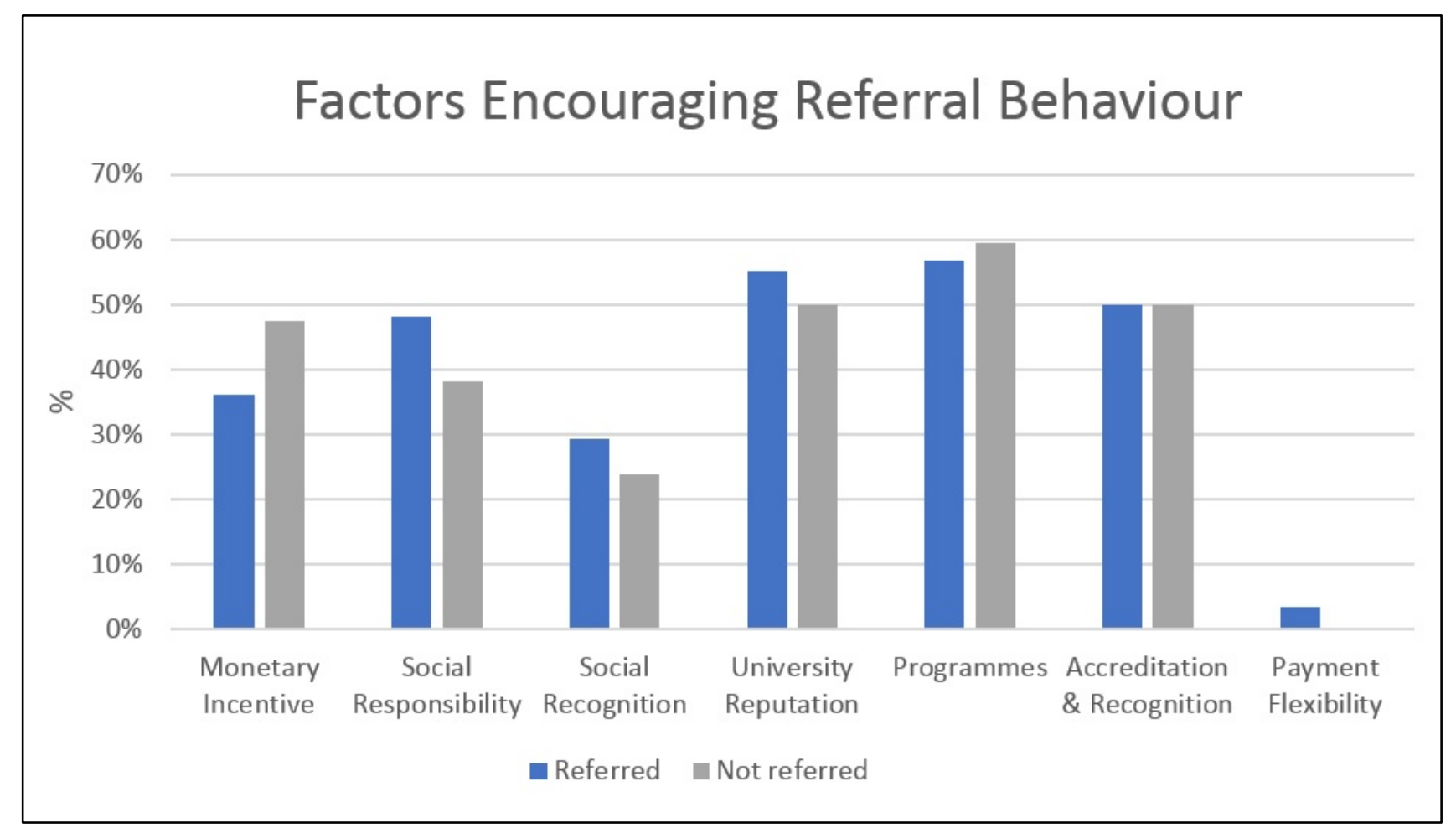

Figure 2. Factors Encouraging Referral Behaviour (source: the authors) 


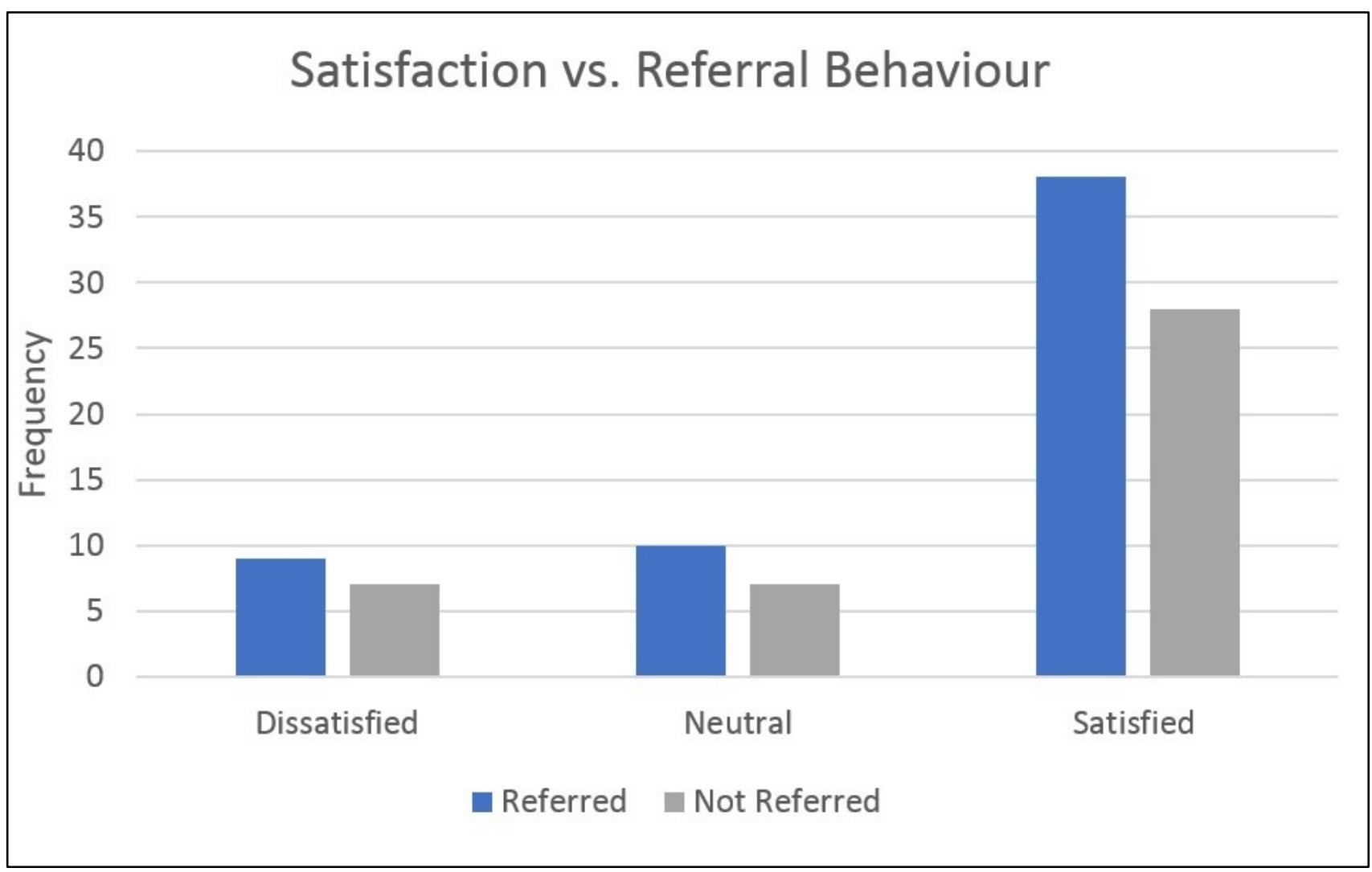

Figure 3. Satisfaction vs. Referral Behaviour (source: the authors)

Interestingly, only $36 \%$ of those who have referred their friends mentioned that the monetary incentive was a driving factor for their behaviour, compared to $48 \%$ of those who had not referred (Figure 2). However, there was no statistically significant association $(\chi 2(1)=$ $0.331, p$ value 0.565$)$. The main factors encouraging referral behaviour for both sources with between 50\%-60\% were the University's reputation, the programmes themselves, and the accreditation/recognition of the programmes.

Moreover, despite the patterns in the data, in the study sample there was no significant difference between Referral Behaviour and Age (LR $(4)=2.053, p=0.726)$, Education level $(\operatorname{LR}(3)=5.769, p=0.123)$, or Gender $(\operatorname{LR}(2)=2.267, p=0.322)$ (Figure 3$)$. 


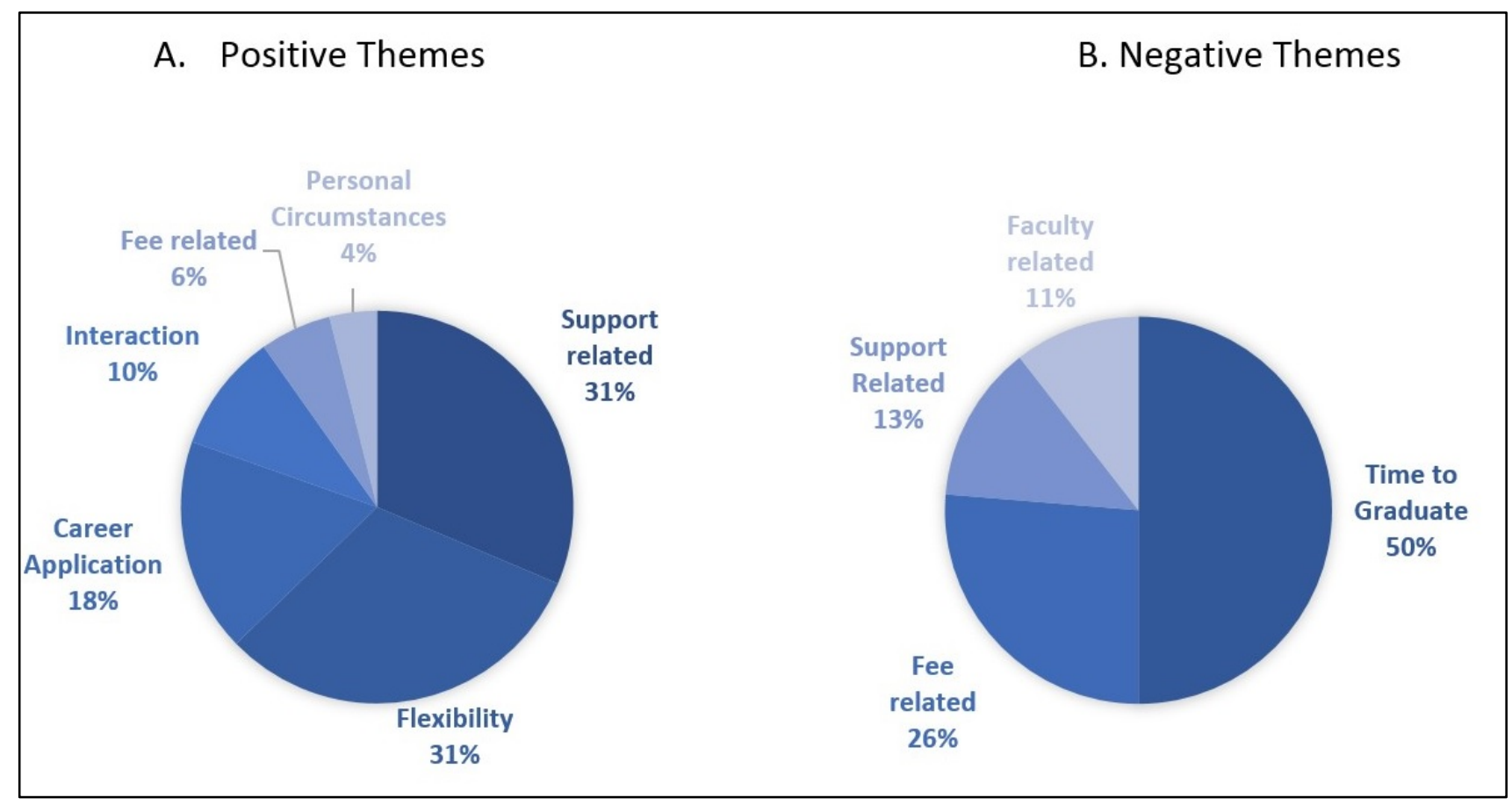

Figure 4. Emergent Positive and Negative Themes from Student Data ( $\mathrm{n}=100)$ (source: the authors)

Given that results from the qualitative interviews found Student Experience was a major contributor to referral behaviour, it was not surprising that events that negatively affect student experience appeared in the emerging negative themes (Figure 4). These themes were extracted from the open-ended questions 'Other (please specify)' and, 'Has your experience so far with the university encouraged or discouraged you from referring? Please briefly explain what encouraged or discouraged you'. Tony (Management, aged 36-45, Barbados), noted that flexibility, practicality and interaction were key. However, he expressed negative feelings towards a unilateral increase in programme fees which he was not expecting.

\section{Incentivisation}

Previous research found that the value of the referral reward does not impact on referral behaviour (Ryu and Feick, 2007), however a more recent study has conflicting findings (Jin and Huang, 2014). Executives routinely mentioned the inconsistency in the referral reward and the incentive itself being main drivers of referral behaviour. It was also suggested that incentivising both parties may increase referral conversion. These findings could simply be reflective of differences in respective fields in existent literature, and/or the extent of purchase involvement, thus even further justifying the rationale behind further investigating $\mathrm{RM}$ behaviour in the $\mathrm{OE}$ sector.

\section{Rapport and Social Network}

A growing focus on rapport was a common theme. Elements which stood out included trust, reliability and support. In total, $100 \%$ of those interviewed either directly or indirectly 


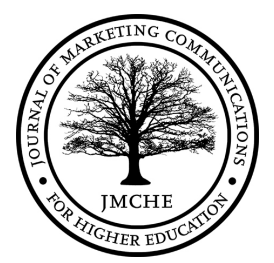

mentioned rapport as a vital factor in RM. In other industries, relationship strength between consumer-consumer and consumer-organisation both have a positive impact on referral behaviour (Shao et al., 2014). Therefore, social networks are also a critical element of referral behaviour, as mentioned by employees repetitively. These findings particularly echo literature on relationship marketing (Almeida-Santana and Moreno-Gil, 2017; Bock and Larson, 2013; Hennig-Thurau et al., 2001), and share similar dimensions. The relationship quality-based student loyalty (RQSL) model by Hennig-Thurau et al. (2001) is defined by three constructs:

1. 'Perceived quality'

2. 'Trust'

3. 'Commitment'

The current study uncovered similar patterns in behavioural student loyalty, with university reputation and programme quality and accreditation and recognition being the top three influential factors for referring deemed by students (Figure 4). Another $18 \%$ of positive themes were attributed to professional applicability which is an element of commitment (Hennig-Thurau et al., 2001) (Figure 4).

Latent elements of SCT were noticed in relation to feedback from executives, mentioning that students from certain cultures or those in management programmes preferred to try the platform themselves before referring others. However, this was not classified as a main theme in either of the data sets. Nevertheless, it could be alternatively linked to the theme of social network, although this is inconclusive in this study. 


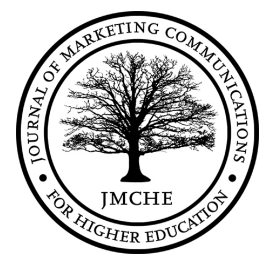

\section{Program Choice}

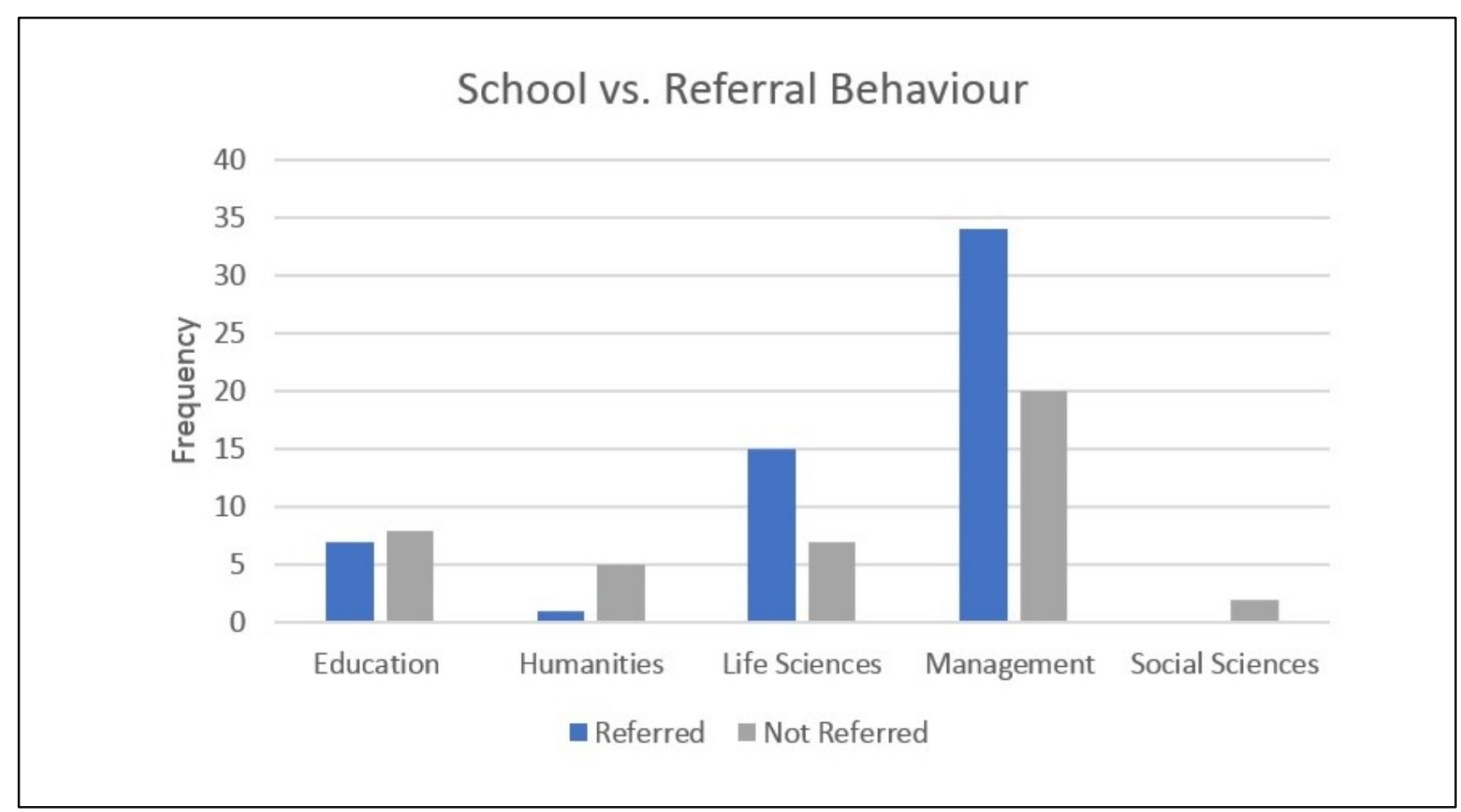

Figure 5. School vs. Referral Behaviour (source: the authors)

Given that executives perceived a higher referral rate from certain programmes, programme choice (grouped into school) was tested and showed a statistically significant association with referral behaviour (LR $(5)=11.214, p=0.047$ ) (Figure 5). Executives also mentioned a perceived interest in helping others was greater for students in certain programmes, however such students were not statistically significantly more influenced by a feeling of social responsibility $(\operatorname{LR}(5)=7.048, p=0.217)$.

Given that executives perceived a higher referral rate from Gulf Cooperation Council (GCC) and African countries and student data was supportive (Figure 6), a Pearson Chi-Square test was done between African vs. referral behaviour as no GCC students participated in the survey; a statistically significant positive association was found $\chi^{2}$ (1) $4.076, p=0.044$. 


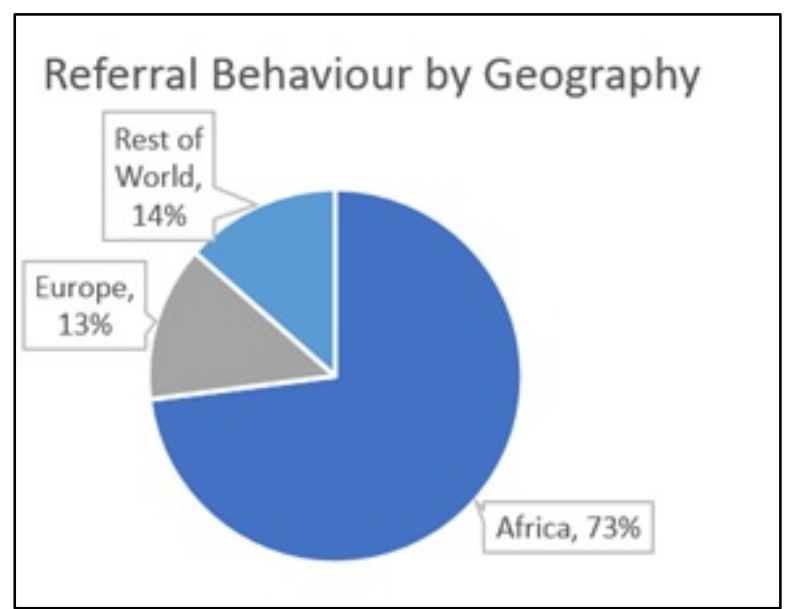

Figure 6. Referral Behaviour by Geography (source: the authors)

Grounded theory (GT) allows for the shaping and reshaping of research design and analysis (Johnson, 2015b). Following this finding, given the referral policy is financially incentivised, to understand if there was any direct correlation between economic climate and referral behaviour, a Wilcoxon-Mann-Whitney test was run for gross domestic product (GDP) vs. referral behaviour. This is because GDP does not follow a normal distribution. The GDP (in millions of USD) assigned was based on the most recent GDP list for 2016 released by The World Bank (2017). Although the mean rank of those who have referred others (47.82) is lower than those that have not (54.20), the 1-tailed probability $(0.138)$ was not statistically significant.

To investigate the impact of collectivism/individualism in culture, primary nationality was sorted into individualistic and collectivist groups (Hofstede, 2003) (Figure 7). A positive statistically significant association between culture (collectivist/individualistic) vs. referral behaviour was $\chi^{2}$ (1) $5.420, p=0.020$. 


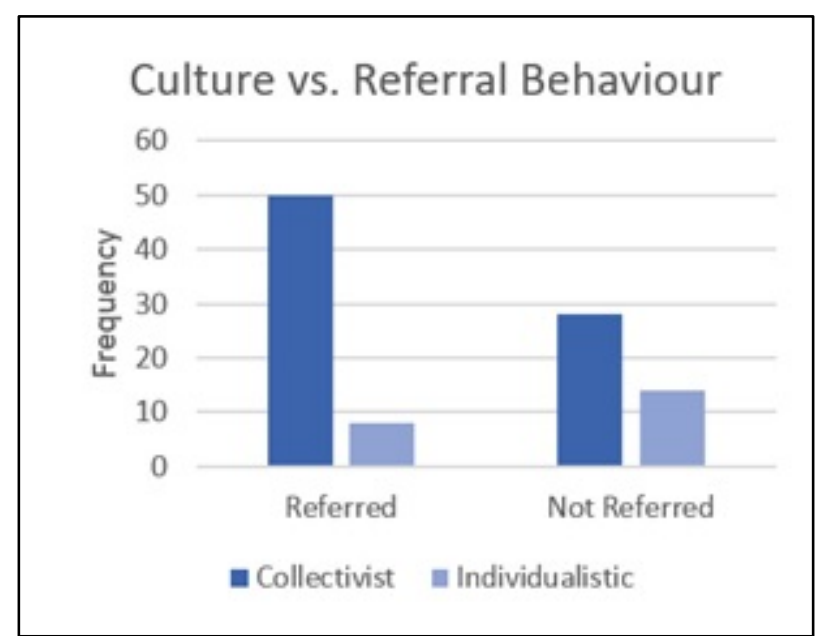

Figure 7. Culture vs. Referral Behaviour (source: the authors)

\section{Other Interesting Findings}

It was noted by a Senior Executive that there was a certain personality type that tended to refer more or act as opinion leaders, which resonated with findings by Song et al (2017). Personality type was not gauged in the survey, however 'social recognition' and 'social responsibility' were choices given. There was no significant difference between those who had referred and those who selected 'social recognition' or 'social responsibility' as a reason for referring. This, therefore, did not reflect elements of SCT. Overall, interviews came across as emotionally-attached, highlighting the emotionally connected nature of employees in this institution. Implications of this are discussed in the next part.

\section{Perceived impact of IMC strategy}

The IMC strategy of this organisation includes digital marketing (social media, email campaigns, website, webinars), phone calls and face-to-face information sessions.

Throughout the interviews, employees mentioned their opinions and observations of how the IMC strategy impacts on RM. Overall, the perceived impact of the current IMC strategy was poor, and was often linked to a perceived negative impact on referral generation, both directly (RM activities) and indirectly (collective student experience) as summed up by employees. This phenomenon appeared to be linked to goal-related conflicts between departments, which was exacerbated by high levels of dissatisfaction with inter-departmental communication. In total $91 \%$ of employees interviewed mentioned challenges related to IMC, and/or inter-departmental communication.

\section{Key trends}

When asked about key trends, employees noted a collective of six main themes: social media, geotargeting, key touch points, focus on budget, video content and technology.

\section{Social Media and Video Content}

The greatest trend discovered was social media. Social media has become a powerful tool for marketers in many sectors and is increasingly used in the Education sector (Clark et al., 


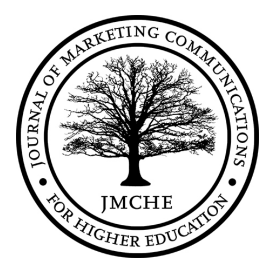

2017). In other industries, social media has highly influenced attitudinal loyalty (AlmeidaSantana and Moreno-Gil, 2017). Most appealing to marketing experts is that it functions as a dynamic, interactive platform for relationship building, EWOM and direct marketing (Alalwan et al., 2017; Clark et al., 2017; Haenlein and Libai, 2017). It also allows for the sharing of video content, which was established as another key trend.

\section{Competition}

A Senior Executive mentioned there had been a decreasing trend in referrals over his past 3.5-year tenure, which he attributed to competition in the rapidly growing sector.

\section{Challenges}

The clear majority of challenges were of an internal nature, therefore falling largely under the institution's control. These included inter-departmental communication, incentive inconsistencies, policies \& systems, economic climate and fee increase. Findings shadow the literature which found EE is affected by process improvements (Gupta, 2015) and interdepartmental communication (De Nobile, 2017).

\section{Opportunities}

Themes on opportunities were collected into Targeting, Social Media and Incentivisation nodes. Outlying the themes above were some interesting suggestions on targeting expat communities, student stories, and data analytics in targeting. Each of these concepts are reflected in recent literature in relation to global marketing strategy, most relevantly by Wright (2014).

\section{Conceptual Model}

Below is the conceptual model proposed by the researchers based on the collated findings discussed (Figure 8). Managerial and theoretical implications are discussed further in the next section.

The proposed conceptual model illustrates the complex interactions between RM constructs in $\mathrm{OE}$. The researchers acknowledge that further understanding is required to define each construct in the wider OE community (outside this case study). However, this model forms the basis of RM phenomena witnessed throughout the study, which includes an important suggested action of OS to mediate employees' 'Belief in Strategy'. If implemented correctly, finely-tuned interactions between the dimensions and constructs should ultimately increase referral behaviour. 


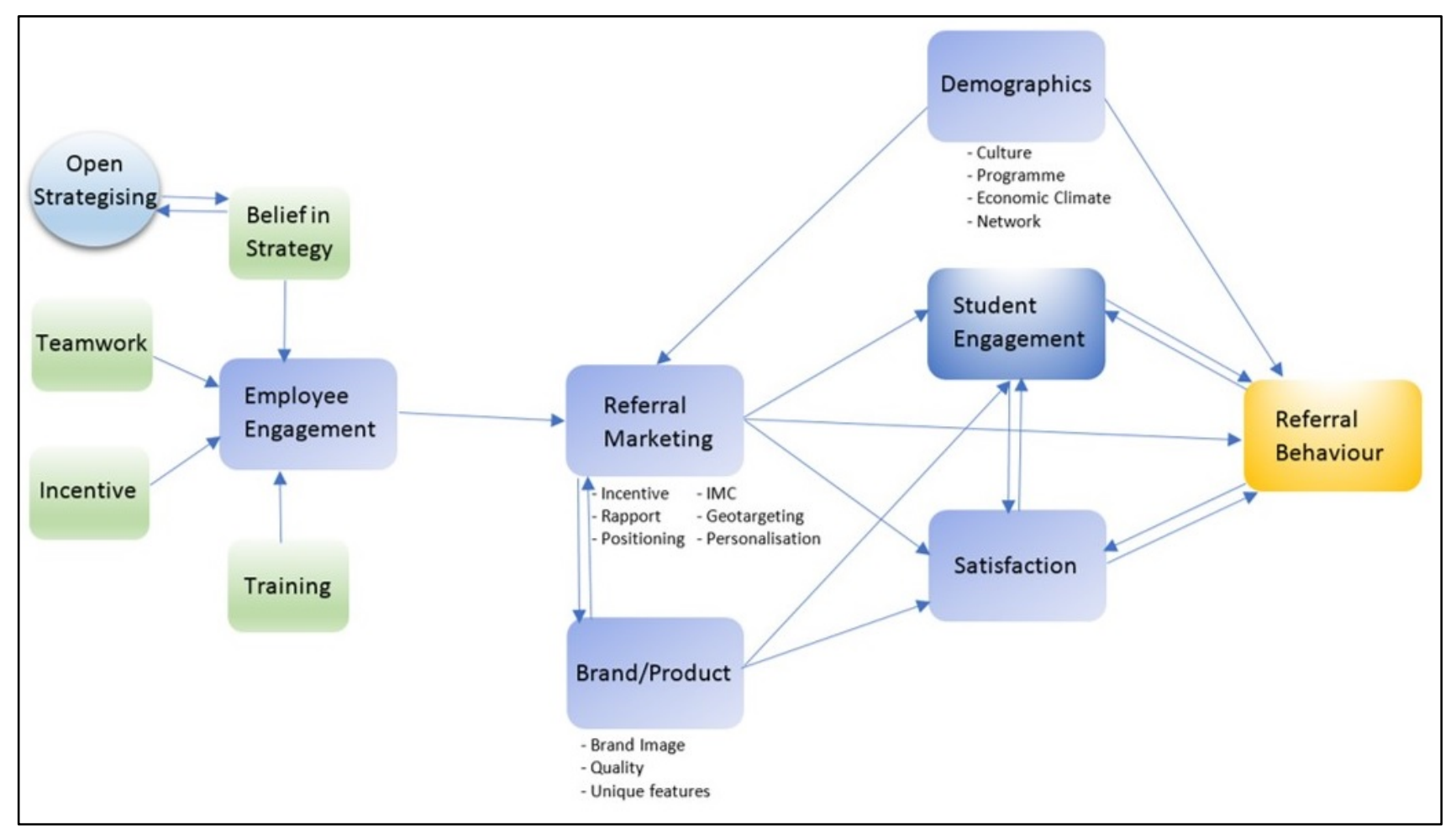

Figure 8. Title: Proposed conceptual model of RM in OE, including main themes of casestudy findings (source: the authors)

\section{Validity and Reliability}

Through a targeted sampling design for both data sets, both samples were deemed to be representative of the respective populations under investigation for this case study as they were assumed to be representative of the population (Easterby-Smith et al., 2012). A larger sample for the student data would have increased the validity and reliability of the findings. By making the survey 'easy and short', ensuring 'confidentiality and anonymity', posting reminders and clearly outlining the purpose (Easterby-Smith et al., 2012) it encouraged responses. Methodological triangulation also assisted in maintaining valid and reliable results within the limitations mentioned by capturing various elements of the same phenomenon. Indeed, a larger sample size can increase validity and reliability, however valid and reliable data can be extracted from 22 interviews (McQuarrie and McIntyre, 2014). A series of chisquare tests and cross-tabulations were conducted to produce reliable and valid results from the sample.

\section{Conclusions}

The findings of this study make key contributions to understanding RM in OE. The key dimensions and relationships discovered have profound meaning for marketers in this industry. They provide a foundation for scholars to further advance knowledge of consumerbrand relationships, CBE, EE, and trust-loyalty behaviour in an industry where students play a unique consumer type. Incentivisation is a key driver of referral behaviour. IMC, video content and social media were found to be perceived as influential in successful RM. 


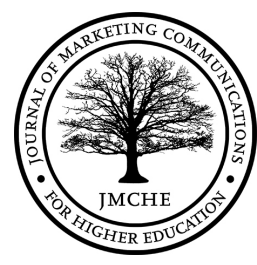

However, their contribution to the studied organisation appeared not to have reached full potential, and thus are considered an opportunity for further development. Personalised outreach at key touchpoints was a common theme throughout the study which links with existing theory (Batra and Keller, 2016) and has interesting managerial implications. It is suggested that a comprehensive IMC strategy is created to include geographically tailored dialogue, and executives are also trained to outreach with personal messaging. Managers must collaborate with other departments which influence RM success in order to increase interdepartmental communication. All of these factors in turn, are expected to increase the success of RM.

\section{Managerial Implications}

Managers are encouraged to increase employees' Belief in Strategy in order to fully achieve commitment to RM and to increase success through increased conversion of referred prospects. EE was influenced by training, teamwork, incentivisation and individual belief in the strategy; a potentially undefined construct which could contribute to EE theory. From reviewing previous literature and from understanding the complex employee environment, the researchers suggest that OS may provide a solution to employee disengagement, thus optimising RM strategy.

Our findings suggest modifying the incentive to reward both parties in a bid to increase referral conversion. In combination, marketing managers must also look to design messaging, or enable executives to hone for certain personality traits (Song et al., 2017). These could greatly increase RM success.

\section{Employee Engagement and Open Strategising}

Due to previously discussed dilemmas of OS (Hautz et al., 2017), managers and strategic leaders must be mindful of the impacts of adopting this approach for RM which may harm team dynamics, individual motivation and organisational commitment if not properly administered. However, given the emotionally attached nature of executives in this case study, and indeed perhaps the larger OE sector, OS may present a realistic solution to EE towards RM strategy. Hanaysha (2016) stipulates that engaged employees are more emotionally attached in this sector, and OS can increase commitment and facilitate a sense of organisational community (Hutter et al., 2017).

\section{Targeting through Social Media, Video and IMC}

Social media and video content are conclusively vital emerging trends in the OE sector and integral contributors to a successful IMC strategy. With social media marketing greatly impacting on trust and loyalty (Orzan et al., 2016), OE marketing managers must embrace social media and use it more comprehensively as part of an RM strategy. This also applies to video content, and face-to-face and virtual events, which provide extra channels to reach consumers and increase CBE (Manser Payne et al., 2017). Another aspect of OS is applied to social media (Baptista et al., 2017), and could potentially be applicable to increasing student engagement with RM in mind. The findings suggested that social media implementation had not yet reached its potential, and therefore posed as another opportunity for development to

(C) 2020 Elise Boros M.S., Angeliki Papasava Ph.D.

This open access article is licensed under a Creative Commons Attribution-NonCommercial license. DOI: JMCHE/vli301 


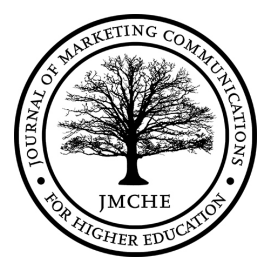

tie in RM. To drive a successful RM strategy, these findings show that Marketers must harness the opportunities of social media at key touchpoints, including more engaging video content, geotargeting and personalisation to strengthen consumer relationships (Alalwan et al., 2017; Clark et al., 2017), whilst keeping interdepartmental lines of communication open to create a well-oiled, comprehensive IMC strategy. Marketers must be cautious of the uncontrolled nature of social media, yet should aim to create an RM dialogue conducive to positive co-creation and CBE. Relating to the findings and to the student-centred tone of executive interviews, the researchers propose it could be more beneficial to adopt a bottomup approach as proposed by Batra, R. \& Keller, K. (2016). Lastly, targeting those who have already referred and those who are satisfied is likely to increase CLV (Wright, 2014).

\section{Big Data Analytics}

As the current study suggests, multinational educational marketers could certainly benefit from extending big data capabilities into RM for the OE niche to better understand complex phenomena in RM and better tailor RM strategy. A challenging prerequisite is certainly the availability of data, and the cloud storage/software to house and analyse it. International consumer privacy is also an ethical issue that must be dealt with carefully (Herschel and Miori, 2017).

\section{Culture, Programme Choice and International Arena}

The impact of Hofstede's (2003) cultural dimensions has been recently applied to organizational profiles in social media (Lo et al., 2017) and the researchers believe collectivism vs. individualism is something that universities with multinational student bodies should take into consideration with particular respect to creating RM strategy. Based on our findings, OE marketers must be more mindful of their audience, as culture plays a large role in the success of RM, as well as programme choice, residency, and economic climate. Since the incentive has a positive association with referral behaviour, and the idea to incentivise both parties was mentioned by employees, it may also be worth experimenting with. Based on the findings, the researchers suggest creating a geographically and culturally tailored IMC strategy specifically for referral generation. Marketing departments should also increase RM efforts in specifically high-referral regions and high-referral programmes in order to maximise returns on marketing spend. Similar to diverse e-commerce consumer types (Zikienè and Kalmakhelidz, 2016) different types of students exist. If OE marketing professionals can master these suggested alterations to existing RM so that they appeal to the diverse student population, increased profitability is likely, as echoed in the literature related to other industries (Gorlevskaya, 2016; Oberoi et al., 2017).

\section{Limitations and Delimitations}

The nature of this case study allowed only for a small number of employee participants, and a small number of student participants due to the survey limitations. Therefore, to make findings more robust, a larger sample of employees, potentially from other universities that offer a referral incentive, could render more insightful data. Further studies are required to collect feedback from more students on the topic of referral behaviour and thus contribute to RM strategy. There was a limitation of using GDP of the nationality given, as the data does

(C) 2020 Elise Boros M.S., Angeliki Papasava Ph.D.

This open access article is licensed under a Creative Commons Attribution-NonCommercial license. DOI: JMCHE/vli301 


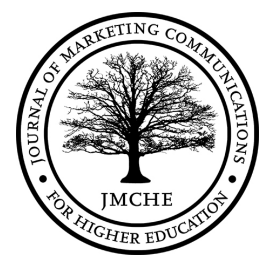

not specify the current location of the student or the individual's income bracket, and thus may be too general of an approach and not truly represent the student body.

\section{Recommendations for Future Research}

With the knowledge gained from the current study, future research could build on the model by Hennig-Thurau et al (2001) with RM in mind. Belief in Strategy is proposed as a potentially new construct, adding to existing EE theory. Therefore, the researchers propose OS as a means to positively influence EE in this industry, and thus further research would be necessary to confirm the relationship. Recently published research by Asrar-ul-Haq et al. (2017) links corporate social responsibility (CSR) in universities to employees' satisfaction and organisational commitment, introducing another potential facet to consider when implementing RM. CSR was not investigated in the current study, however given this valid perspective has been highlighted in newly published research, further investigation into this dimension in relation to OS, EE and RM may prove fruitful for marketing managers. As our findings suggest, if an organisation can use a comprehensive IMC strategy which reaches out to students at key touchpoints to build a powerful brand image, this is likely to positively influence referral behaviour. 
Vol 1 Issue 3 (2020)

\section{References}

Alalwan, Ali Abdallah et al. 2017. "Social media in marketing: A review and analysis of the existing literature". Telematics and Informatics 34 (7): 1177-1190. Elsevier BV. doi:10.1016/j.tele.2017.05.008.

Almeida-Santana, Arminda \& Moreno-Gil, Sergio. 2017. "New trends in information search and their influence on destination loyalty: Digital destinations and relationship marketing". Journal of Destination Marketing \& Management 6 (2): 150-161. Elsevier BV. doi:10.1016/j.jdmm.2017.02.003.

Asrar-ul-Haq, Muhammad; Kuchinke, K. Peter \& Iqbal, Anam. 2017. "The relationship between corporate social responsibility, job satisfaction, and organizational commitment: Case of Pakistani higher education". Journal of Cleaner Production 142: 2352-2363. Elsevier BV. doi:10.1016/j.jclepro.2016.11.040.

Baptista, João et al. 2017. "Social Media and the Emergence of Reflexiveness as a New Capability for Open Strategy". Long Range Planning 50 (3): 322-336. Elsevier BV. doi:10.1016/j.lrp.2016.07.005.

Batra, Rajeev \& Keller, Kevin Lane. 2016. "Integrating Marketing Communications: New Findings, New Lessons, and New Ideas". Journal of Marketing 80 (6): 122-145. SAGE Publications. doi:10.1509/jm.15.0419.

Baxter, Pamela., \& Jack, Susan. (2008) "Qualitative Case Study Methodology: Study Design and Implementation for Novice Researchers". The Qualitative Report, 13(4), pp. 544559.

Berman, Barry. 2016. "Referral marketing: Harnessing the power of your customers". Business Horizons 59 (1): 19-28. Elsevier BV. doi:10.1016/j.bushor.2015.08.001.

Bone, Sterling A. et al. 2017. "“Mere Measurement Plus": How Solicitation of Open-Ended Positive Feedback Influences Customer Purchase Behavior". Journal of Marketing Research 54 (1): 156-170. SAGE Publications. doi:10.1509/jmr.14.0232.

Braun, Virginia \& Clarke, Victoria. 2006. "Using thematic analysis in psychology". Qualitative Research in Psychology 3 (2): 77-101. Informa UK Limited. doi:10.1191/1478088706qp063oa.

Bock, Dora \& Larson, Lindsay. (2013) “Audubon Hill: A relationship marketing case study". Journal Of The International Academy For Case Studies. 19(7) pp. 55-61.

(C) 2020 Elise Boros M.S., Angeliki Papasava Ph.D.

This open access article is licensed under a Creative Commons Attribution-NonCommercial license.

DOI: JMCHE/vli301 


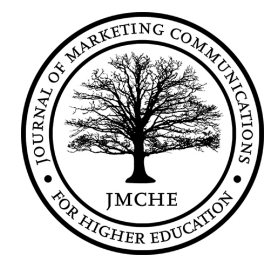

Brooks, Joanna et al. 2014. "The Utility of Template Analysis in Qualitative Psychology Research". Qualitative Research in Psychology 12 (2): 202-222. Informa UK Limited. doi:10.1080/14780887.2014.955224.

Burr, Viven. (2015) Social Constructionism. London: Routledge.

Butcher, Lola. (2011) “The Rapid Growth of MD/MBA Programs: Are They Worth It?”. Physician Executive. 37(1) pp. 22-26.

Byrne, David., \& Ragin, Charles. (2009) The SAGE Handbook of Case-Based Methods. Newbury Park, CA: Sage.

Campbell, Donald T \& Stanley, Julian C. 2011. Experimental and quasi-experimental designs for research. Belomt: Wadsworth.

Chan, Simon T. H.; Lin, Tom M. Y. \& Bodhi, Priy. 2014. "Exploring the Persuasive Effect of Member-Get-Member Referral Programs". Social Behavior and Personality: an international journal 42 (6): 891-901. Scientific Journal Publishers Ltd. doi:10.2224/sbp.2014.42.6.891.

Chowdhury, Ilma Nur; Gruber, Thorsten \& Zolkiewski, Judy. 2016. "Every cloud has a silver lining - Exploring the dark side of value co-creation in B2B service networks". Industrial Marketing Management 55: 97-109. Elsevier BV. doi:10.1016/j.indmarman.2016.02.016.

Chu, Kevin. 1999. "An introduction to statistics, significance testing and the $\mathrm{P}$ value". Emergency Medicine Australasia 11 (1): 28-34. Wiley. doi:10.1046/j.14422026.1999.00316.x.

Clark, Melissa; Fine, Monica B. \& Scheuer, Cara-Lynn. 2016. "Relationship quality in higher education marketing: the role of social media engagement". Journal of Marketing for Higher Education 27 (1): 40-58. Informa UK Limited. doi:10.1080/08841241.2016.1269036.

Claus, Bart et al. 2012. "The referral backfire effect: The identity-threatening nature of referral failure". International Journal of Research in Marketing 29 (4): 370-379. Elsevier BV. doi:10.1016/j.ijresmar.2012.06.004.

Cossío-Silva, Francisco-José et al. 2016. "Value co-creation and customer loyalty". Journal of Business Research 69 (5): 1621-1625. Elsevier BV. doi:10.1016/j.jbusres.2015.10.028. 


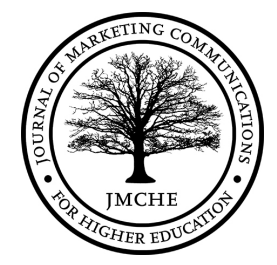

Daj, Alexis \& Chirca, Andreea. (2009) "E-marketing tools and the new dimension of integrated marketing communications in European higher education services". Problems Of Education In The 21St Century. 12 pp. 36-45.

De Nobile, John. (2017) "Organisational communication and its relationships with job satisfaction and organisational commitment of primary school staff in Western Australia”. Educational Psychology. 37(3) pp. 380-398.

Drouin, Michelle; Stewart, Jennifer \& Van Gorder, Karen. 2015. "Using methodological triangulation to examine the effectiveness of a mentoring program for online instructors". Distance Education 36 (3): 400-418. Informa UK Limited. doi:10.1080/01587919.2015.1081735.

Dwivedi Abhishek. (2015) "A higher-order model of consumer brand engagement and its impact on loyalty intentions". Journal Of Retailing And Consumer Services. 24 pp. 100-109.

Easterby-Smith, Mark; Jackson, Paul \& Thorpe, Richard. (2012) Management research.

Fong, James. (2013) "Preparing Marketing for the Future: Strategic Marketing Challenges for Continuing Education”. New Directions For Adult \& Continuing Education. 140 pp. 89-100.

Gast, Arne \& Zanini, Michele. (2012) “The social side of strategy”. McKinsey Quarterly.

Graffigna, Guendalina \& Gambetti, Rosella. (2015) "Grounding consumer-brand engagement”. International Journal Of Market Research. 57(4) pp. 605-629.

Gorlevskaya, Liudmila. (2016) "Building Effective Marketing Communications in Tourism". Studia Commercialia Bratislavensia. 9(35) pp. 252-265.

Gupta, Madhulika. (2015) “A study on employees' perception towards employee engagement”. Globsyn Management Journal. 9(1/2) pp. 45-51.

Haase, Tina; Termath, Wilhelm \& Martsch, Marcel. 2013. "How to Save Expert Knowledge for the Organization: Methods for Collecting and Documenting Expert Knowledge Using Virtual Reality based Learning Environments". Procedia Computer Science 25: 236-246. Elsevier BV. doi:10.1016/j.procs.2013.11.029.

Haenlein, Michael \& Libai, Barak. (2017) "Seeding, Referral, and Recommendation: Creating profitable word-of-mouth programs". California Management Review. 59(2) pp. 68-91. 


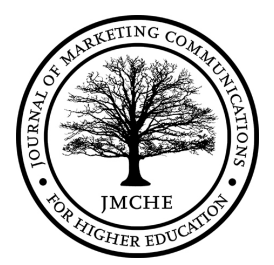

Hanaysha, Jalal. (2016) "Examining the effects of Employee Empowerment, Teamwork, and Employee Training on Organizational Commitment". Procedia - Social And Behavioral Sciences. 229, pp 298-306.

Hardy, Melissa \& Bryman, Alan. (2009) Handbook of data analysis. London: Sage.

Hautz, Julia, Seidl, David \& Whittington, Richard. (2017) “Open Strategy: Dimensions, Dilemmas, Dynamics”. Long Range Planning. 50(3) pp. 298-309.

Herriott, Robert E. \& Firestone, William A. 1983. "Multisite Qualitative Policy Research: Optimizing Description and Generalizability". Educational Researcher 12 (2): 14. American Educational Research Association (AERA). doi:10.2307/1175416.

Hennig-Thurau, Thorsten., Langer, Markus. \& Hansen, Ursula. (2001) "Modeling and managing student loyalty: An approach based on the concept of relationship quality". Journal of Service Research. 3(4), pp. 331- 344.

Herschel, Richard \& Miori, Virginia. (2017) "Ethics \& Big Data”. Technology In Society. 49 pp. 31-36.

Hinge (2014) Professional Services Marketing Today: In-Depth Interview vs Online Survey: A Marketing Director's Guide to Brand Research Data Collection.

Hollebeek, Linda. (2011) "Demystifying customer brand engagement: Exploring the loyalty nexus”. Journal Of Marketing Management. 27(7-8) pp. 785-807.

Hsieh, Sara \& Chang, Aihwa. (2016) "The Psychological Mechanism of Brand Co-creation Engagement”. Journal Of Interactive Marketing. 33 pp. 13-26.

Hsieh, Ming-Tsang \& Tsao, Wen-Chin. (2014) "Reducing perceived online shopping risk to enhance loyalty: a website quality perspective". Journal Of Risk Research. 17(2) pp. 241-261.

Hung, Kineta \& Yiyan Li, Stella. (2007) “The Influence of eWOM on Virtual Consumer Communities: Social Capital, Consumer Learning, and Behavioral Outcomes". Journal Of Advertising Research. 47(4) pp. 485-495.

Hutter, Katja, Nketia, Bright \& Füller, Johann. (2017) "Falling Short with Participation Different Effects of Ideation, Commenting, and Evaluating Behavior on Open Strategizing". Long Range Planning. 50(3) pp. 355-370.

Hofstede, Geert. (2003) Culture's consequences: Comparing values, behaviors, institutions and organizations across nations. Thousand Oaks: Sage.

(C) 2020 Elise Boros M.S., Angeliki Papasava Ph.D.

This open access article is licensed under a Creative Commons Attribution-NonCommercial license.

DOI: JMCHE/vli301 


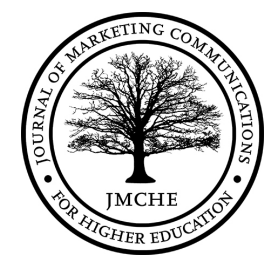

Ilgaz, Hale \& Gülbahar, Yasemin. (2015) "A Snapshot of Online Learners: e-Readiness, eSatisfaction and Expectations". International Review Of Research In Open \& Distance Learning. 16(2) pp. 171-187.

Jin, Liyin \& Huang, Yunhui. (2014) "When giving money does not work: The differential effects of monetary versus in-kind rewards in referral reward programs". International Journal of Research in Marketing. 31(1) pp 107-116.

Johnson, Jeff. (2015a) "Broadening the application of mixed methods in sales research". Journal Of Personal Selling \& Sales Management. 35(4) pp. 334-345.

Johnson, Jeff. (2015b) "Qualitative sales research: an exposition of grounded theory". Journal Of Personal Selling \& Sales Management. (35(3) pp. 262-273.

Johnson Burke \& Onwuegbuzie, Anthony. (2004) "Mixed Methods Research: A Research Paradigm Whose Time Has Come". American Educational Research Association. 33(7) pp. 14-26.

Johnstone, Elaine, K. \& Ruane, Lorna. (2013) "Generation Y females online: insights from brand narratives". Qualitative Market Research: An International Journal. 16(3) pp. 315-335.

Juntunen, Mari \& Malewar, T.C. 2014. "Interpretative narrative process research approach to corporate renaming". Qualitative Market Research: An International Journal 17 (2): 112-127. Emerald. doi:10.1108/qmr-12-2013-0088.

Kaiser, Carolin, Kröckel, Johannes \& Bodendorf, Freimut. (2013) "Simulating the spread of opinions in online social networks when targeting opinion leaders". Information Systems \& E-Business Management. 11(4) pp. 597-621.

Kaur, Sukhmeet. (2017) “Antecedents and Consequences of Employee Engagement: A Literature Review”. IUP Journal Of Organizational Behavior. 16(3) pp. 7-32.

Khouly, Sayed \& Fadl, Noha. (2016) “The Impact of Organizational Culture on Work Quality”. Competition Forum. 14(2) pp. 210-215.

Kibelloh, Mboni \& Bao, Yukun. (2014) "Can Online MBA Programmes Allow Professional Working Mothers to Balance Work, Family, and Career Progression? A Case Study in China”. Asia-Pacific Education Researcher. 23(2) pp. 249-259.

Kim, Yong \& Tran, Vinh. (2013) "Assessing the ripple effects of online opinion leaders with trust and distrust metrics”. Expert Systems With Applications. 40 (9) pp. 3500-3511. 


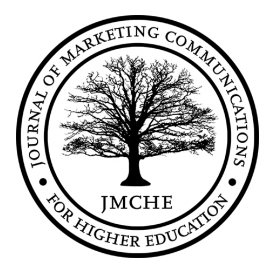

Leckie, Civilai, Nyadzayo, Munyaradzi \& Johnson, Lester. (2016) "Antecedents of consumer brand engagement and brand loyalty". Journal Of Marketing Management. 32(5-6) pp. 558-578.

Lee, Jungki \& Anantharaman, Sekhar. (2015) "MBA Students' engagement behavior and its implications on student loyalty to Alma Mater". Academy Of Marketing Studies Journal. 19(2) pp. 103-116.

Lincoln, Yvonna \& Guba, Egon. (1989) Ethics: The Failure of Positivist Science. The Review of Higher Education, 12(3), pp.221-240.

Lo, Kevin, Waters, Richard \& Christensen, Nicklas (2017) "Assessing the applicability of Hofstede's cultural dimensions for Global 500 corporations' Facebook profiles and content”. Journal Of Communication Management. 21(1) pp. 51-67.

Lobstein, Tim et al. 2016. "The commercial use of digital media to market alcohol products: a narrative review". Addiction 112: 21-27. Wiley. doi:10.1111/add.13493.

Luxton, Sandra; Reid, Mike \& Mavondo, Felix. 2014. "Integrated Marketing Communication Capability and Brand Performance". Journal of Advertising 44 (1): 37-46. Informa UK Limited. doi:10.1080/00913367.2014.934938.

Manser Payne, Elizabeth, Peltier, James \& Barger, Victor. (2017) "Omni-channel marketing, integrated marketing communications and consumer engagement". Journal Of Research In Interactive Marketing. 11(2) pp. 185-197.

Mazzarol, Tim \& Soutar, Geoffrey. (2002) "Push-pull” factors influencing international student destination choice". International Journal of Educational Management. 16(2) pp.82-90.

McQuarrie, Edward \& McIntyre, Shelby (2014) "What Can You Project from Small Sample Qualitative Research?”. Marketing Insights. 26(2) pp. 34-39.

NVIVO (2017a) What is NVIVO? Available at: http://www.qsrinternational.com/what-isnvivo

NVIVO (2017b) How are cluster analysis diagrams generated?

Oberoi, Poonam; Patel, Chirag \& Haon, Christophe. 2017. "Technology sourcing for website personalization and social media marketing: A study of e-retailing industry". Journal of Business Research 80: 10-23. Elsevier BV. doi:10.1016/j.jbusres.2017.06.005.

Oliver, Richard. (2014) Satisfaction: A Behavioral Perspective on the Consumer, New York: Armonk. 
Orzan, Gheorghe et al. (2016) "Conceptual model regarding the influence of social media marketing communication on brand trust, brand affect and brand loyalty". Economic Computation \& Economic Cybernetics Studies \& Research. 50(1) pp. 141-156.

Pénard, Thierry \& Poussing, Nicolas. (2010) "Internet Use and Social Capital: The Strength of Virtual Ties”. Journal Of Economic Issues. 44(3) pp. 569-595.

Perin, Marcelo Gattermann et al. 2012. "Modeling antecedents of student loyalty in higher education". Journal of Marketing for Higher Education 22 (1): 101-116. Informa UK Limited. doi:10.1080/08841241.2012.705797.

Petrovčič, Andraž; Petrič, Gregor \& Lozar Manfreda, Katja. 2016. "The effect of email invitation elements on response rate in a web survey within an online community". Computers in Human Behavior 56: 320-329. Elsevier BV. doi:10.1016/j.chb.2015.11.025.

Potter, Jonathan \& Wetherell, Margaret (1987) Discourse and social psychology: Beyond attitudes and behaviour. London: Sage.

Reed, Kendra, Goolsby, Jerry \& Johnston, Michelle. (2016) "Listening in and out: Listening to customers and employees to strengthen an integrated market-oriented system". Journal Of Business Research. 69(9) pp. 3591-3599.

Reichheld, Frederick. (1993) “Loyalty-based management”. Harvard Business Review, 71(2), 64-73.

Robinson, Jill \& Norris, Nigel. (2001) "Generalisation: the linchpin of evidence-based practice?". Educational Action Research, 9(2), pp. 303-310.

Rouyendegh, Babak \& Erkan,Turan. (2011) "MBA Students' preference on: online, formal and hybrid MBA programs". Procedia - Social And Behavioral Sciences. 28 pp. 770775.

Ruddin, Lee Peter. (2006) "You Can Generalize Stupid! Social Scientists, Bent Flyvbjerg, and Case Study Methodology". Qualitative Inquiry, 12(4), pp. 797-812.

Ryu, Gangseog \& Feick, Lawrence. (2007) “A Penny for Your Thoughts: Referral Reward Programs and Referral Likelihood". Journal of Marketing. 71 (1) 84-94.

Sarathy, Sanjai \& Patro, Sanjai (2013) “The Role of Opinion Leaders in High-Involvement Purchases: An Empirical Investigation”. South Asian Journal Of Management. 20(2) pp. 127-145. 


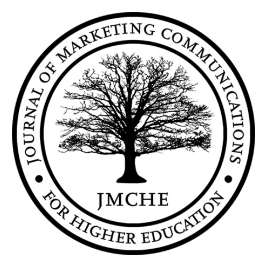

Schaap, H. et al. 2011. "Explicating Students' Personal Professional Theories in Vocational Education through Multi-method Triangulation". Scandinavian Journal of Educational Research 55 (6): 567-586. Informa UK Limited. doi:10.1080/00313831.2011.555922.

Schmitt, Philipp, Skiera, Bernd \& Van den Bulte, Christoph. (2011) "Referral Programs and Customer Value.” Journal Of Marketing. 75(1) pp. 46-59.

Schumann, Jan H. et al. 2010. "Cross-Cultural Differences in the Effect of Received Wordof-Mouth Referral in Relational Service Exchange". Journal of International Marketing 18 (3): 62-80. SAGE Publications. doi:10.1509/jimk.18.3.62.

Shah, Mahsood, et al. (2014) "Widening Student Participation in Higher Education through Online Enabling Education”. Widening Participation \& Lifelong Learning. 16(3) pp. 36-57.

Shao, Jing-bo, Zhang, Jun-hui \& Guo, Bei-bei. (2014) "Research on the influencing factors of customer referral behavior based on social network-Application in the catering industry". Journal Of High Technology Management Research. 25(2) pp. 163-171.

Sheldon, Neil, Lincoln, Yvonna \& Guba, Egon. (1986) "Naturalistic Enquiry". The Statistician, 35(3), pp.395.

Shi, Mengze \& Wojnicki, Andrea. (2014) "Money Talks ... to Online Opinion Leaders: What Motivates Opinion Leaders To Make Social-Network Referrals?". Journal Of Advertising Research. 54(1) pp. 81-91.

Song, So-Yung, Cho, Erin \& Kim, Yun-Kyung. (2017) "Personality factors and flow affecting opinion leadership in social media". Personality And Individual Differences. 114 pp. 16-23.

Steinberg, Paul (2015). “Can We Generalize from Case Studies?”. Global Environmental Politics, 15(3), pp.152-175.

Strauss, Judy \& Frost, Raymond. (2013) E-Marketing. ( $7^{\text {th }}$ ed.) Upper Saddle River: Pearson.

Symon, Gillian \& Cassel, Catherine. (2012) Qualitative Organizational Research: Core Methods and Current Challenges. London: Sage.

Tan, S. \& Lau, Chong. (2012) "The Impact of Performance Measures on Employee Fairness Perceptions, Job Satisfaction and Organisational Commitment”. Journal Of Applied Management Accounting Research. 10(2) pp. 57-72. 


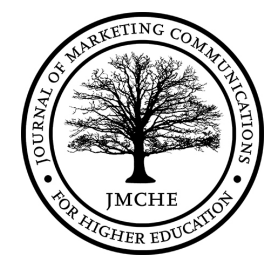

The World Bank (2017) GDP Ranking. Available at: http://data.worldbank.org/datacatalog/GDP-ranking-table (Accessed: 5/07/2017).

Verlegh, Peeter, et al. (2013) "Receiver responses to rewarded referrals: The motive inferences framework". Journal Of The Academy Of Marketing Science. 41(6) pp. 669-682.

Vernuccio, Maria \& Ceccotti, Federica. (2015) "Strategic and organisational challenges in the integrated marketing communication paradigm shift: A holistic vision". European Management Journal. 33(6) pp. 438-449.

Vivek, Shiri, Beatty, S.E. \& Morgan, Robert. (2012) "Customer Engagement: Exploring Customer Relationships Beyond Purchase”. Journal Of Marketing Theory \& Practice. 20(2) pp. 122-146.

Waring, Teresa \& Wainwright, David. (2008) "Issues and challenges in the use of template analysis: Two comparative case studies from the field". The Electronic Journal of Business Research Methods. 6(1) pp. 85-94.

Wedel, Michelle \& Kannan, P.K. (2016) "Marketing Analytics for Data-Rich Environments". Journal Of Marketing. 80(6) pp. 97-121.

Wikfeldt, Emma. (2019). Generalising from Case Studies. [online] Core.ac.uk. Available at: https://core.ac.uk/display/81029999

Wind, Yoram \& Hays, Catharine. (2016) 'Research implications of the 'beyond advertising' paradigm: A model and roadmap for creating value through all media and non-media touchpoints”. Journal Of Advertising Research. 56(2) pp. 142-158.

Wladis, Claire \& Samuels, Jason. (2016) "Do online readiness surveys do what they claim? Validity, reliability, and subsequent student enrollment decisions". Computers \& Education. 98 pp. 39-56.

Woodside, Arch. (2010) Case Study Research: Theory, Methods, Practice. Bingley, UK: Emerald.

Wright, Robert. (2014) "Student focused marketing: Impact of marketing higher education based on student data and input". College Student Journal. 48(1) pp. 88-93.

Yang, Hsiao-Pei \& Mutum, Dilip. (2015) "Electronic word-of-mouth for university selection”. Journal Of General Management. 40(4) pp. 23-44.

Yin, Robert. (2013) "Validity and generalization in future case study evaluations". Evaluation, 19(3), pp. 321-332. 
Yoo, Chul Woo, Kim, Yong Jin \& Sanders, Lawrence. (2015) "The impact of interactivity of electronic word of mouth systems and E-Quality on decision support in the context of the e-marketplace". Information \& Management. 52(4) pp. 496-505.

Zikienė, Kristina \& Kalmakhelidze, Levan. (2016) “Types of Digital Consumers:

Peculiarities in the Context of Online Sales Promotion". Applied Economics: Systematic Research. 10(2) pp. 47-57.

Zwass, Vladimir. (2010) "Co-Creation: Toward a Taxonomy and an Integrated Research Perspective”. International Journal Of Electronic Commerce. 15(1) pp. 11-48. 


\section{List of Figure Captions}

1. Figure 1. Mind map of RM Dimensions from an executive's perspective

2. Figure 2. Factors encouraging referral behaviour split by students who have/haven't referred $(n=100)$

3. Figure 3. Referral behaviour compared with satisfaction $(n=100)$

4. Figure 4. Emergent positive and negative themes from student data $(n=100)$

5. Figure 5. Number of students who have referred others, grouped by school $(n=100)$

6. Figure 6. Percentage of students who have referred others depending on geography $(n=100)$

7. Figure 7. Number of students who have referred others depending on culture $(n=100)$

8. Figure 8: Proposed conceptual model of RM in OE, including main themes of casestudy findings 